DOI: http://dx.doi.org/10.22484/2177-5788.2017v43n1p55-70

\title{
Por uma política da diversidade no campo contemporâneo da comunicação e da cultura
}

Débora Mestre

Paula Parra

Wilton Garcia

Resumo: O presente texto apresenta um ensaio crítico sobre política da diversidade no campo contemporâneo da comunicação e da cultura, ao ressaltar desafios na agenda acadêmico-científica. Trata-se de um exercício de escrita cuja estratégia é o formato ensaio, como percurso metodológico, que visa o debate acerca da nossa sociedade atual. $O$ foco deste estudo equaciona a noção de diversidade - entre alteridade, diferença e transgressão - recorrentes nos estudos contemporâneos. Tais estudos são trabalhados a partir dos estudos culturais e das tecnologias emergentes. Essa ideia de diversidade, hoje, torna-se rica fonte de discussão acerca das mediações do sujeito queer para além do sistema hegemônico. As resultantes destacam uma perspectiva crítica a respeito da diversidade cultural/sexual atualmente.

Palavras-chave: Comunicação e cultura. Política da diversidade.

\section{For a diversity policy in the contemporary field of communication and culture}

Abstract: This paper presents a critical essay on diversity politics in the contemporary field of communication and culture, highlighting challenges in the academic-scientific agenda. It is a writing exercise whose strategy is the essay format, as a methodological course, that aims the debate about our current society. The focus of this study equates the notion of diversity - between alterity, difference and transgression recurrents in contemporary studies. These studies are based on cultural studies and emerging technologies. This idea of diversity today becomes a rich source of debate about the mediations of the queer subject beyond the hegemonic system. The results highlight a critical perspective on cultural/sexual diversity actually.

Keywords: Communication and Culture. Diversity Policy. 
Se é possível arquitetar - projetar e/ou desenhar - uma trajetória flexível e deslocável à vida humana nos dias de hoje, a política enuncia a articulação de nossa sociedade, ainda mais no Brasil. Mesmo diante de uma crise política e econômica no país, é preciso caminhar. O desenvolvimento humano requer habilidades para superar adversidades. E, se assim o for, a política estabelece um instigante princípio emergencial, como fator recorrente da produção de informação e consumo, em especial no campo contemporâneo da comunicação e da cultura. Mais que isso, essa produção da informação viabiliza-se pela cultura digital, particularmente pelas redes sociais.

$\mathrm{Na}$ inauguração deste texto, a epígrafe aponta para a produção de conhecimento associada à produção de libido. $\mathrm{O}$ que facilitaria atrelar à produção de subjetividade, porque se adequa à curiosidade do sujeito. Entre conhecimento, libido, curiosidade e sexo, instaura-se a experimentação com o mundo flutuante de (im)possibilidades, longe de qualquer certeza e/ou precisão.

Surge, assim, uma inquietação em forma de pergunta: como propor uma política da diversidade no campo contemporâneo da comunicação e da cultura, em particular no Brasil?

Com isso, o presente texto apresenta um ensaio crítico sobre política da diversidade no campo contemporâneo da comunicação e da cultura, ao ressaltar desafios na agenda acadêmicocientífica. Nesse contexto, conforme Santos (2014), verifica-se uma expectativa de fomentar politicamente a visibilidade e a ação afirmativa da condição queer, exposta ao longo do texto.

Trata-se de um exercício de escrita cuja estratégia é o formato ensaio, que segundo Canclini (2016), como percurso metodológico, visa o debate acerca da nossa sociedade atual, ao iluminar um ato peculiar da diversidade que tange alteridade e diferença. O que não é nada fácil! Como condição adaptativa, o ensaio inclui apontamentos teóricos e políticos para promover um posicionamento intelectual e social. Essa opção enquadra parâmetros dispostos no encontro de leitura, reflexão e discussão, os quais convergem em um relato de experimentações poéticas como escritura aberta. Nessa perspectiva, para Garcia (2014), o ensaio produz e potencializa o pensar, pautado por substratos da diferença. 
Dessa maneira, o foco deste estudo equaciona a noção de diversidade, conforme Butler, (2008); Foucault (2011); Garcia (2012); Hoff (2016); Louro (2004); Muñoz (1999); Pelbart (2013; 2015); Preciado (2014); Salih (2015) e Santos (2014) - entre alteridade, diferença e transgressão - recorrentes nos estudos contemporâneos, em Bauman (2015); Canclini, 2016; Eagleton (2016); Giannetti (2016); Gumbrecht (2015; 2010); Hall (2002); Lazzarato (2014); Oliveira (2016); Pikkety (2015); Rendueles (2016); Vargas Llosa (2013) e Yúdice (2016).

Esses estudos sobre a contemporaneidade são entrelaçados, estrategicamente, por estudos culturais e tecnologias emergentes. A pesquisa de tais estudos indicados abrange estratégias teórico-metodológicas, as quais estratificam instâncias axiológicas, epistemológicas e ontológicas. E tem como embasamento a noção de contemporâneo (re)dimensionada, segundo Gumbrecht (2015), a partir da noção de cronótopo, espaço-tempo fragmentado e não linear -, portanto, desreferencializado, destotalizado e/ou desmaterializado. Nesse conjunto de inscrições teórico-metodológicas sobre o contemporâneo, verifica-se a articulação recorrente de feixes de efeito entre o efêmero, o parcial, o provisório e o inacabado.

Da produção de conhecimento à produção de subjetividade, a informação perfaz aspectos econômicos, identitários, socioculturais e/ou políticos. Este último, o político, deve ser visto/lido diante das relações em que sujeito e corpo são/estão presentes, porque são relações humanas que legitimam o campo contemporâneo da comunicação e da cultura ${ }^{1}$. Ou seja, a política enquadra a fluidez da polis - na articulação da cidade e seus habitantes. Uma política da diversidade, nesse contexto, desenvolve eminentemente um olhar crítico sobre a desigualdade social, ainda mais no Brasil. Do esvaziamento de sentido aos recursos técnicos, estéticos e/ou éticos, a diversidade compreende fatores inerentes às propriedades emblemáticas e/ou simbólicas, âneo da comunicação e da cultura.

Realizadas essas primeiras anotações, passamos a abordar impressões, discussões e reflexões dessa experimentação investigativa a respeito da diversidade, sobretudo na comunicação e na cultura no contemporâneo. São circunstâncias e derivativas necessárias à composição das ideias, paulatinamente previstas e, por ora, expostas.

\footnotetext{
${ }^{1}$ As anotações estabelecidas neste texto são escritas provenientes de parte das leituras e das discussões realizadas na disciplina Comunicação, consumo e subjetividades (ministrada pelo Wilton Garcia), no primeiro semestre de 2017, no Programa de Comunicação e Cultura da Universidade de Sorocaba - Uniso.
} 


\section{Da diversidade}

A ideia de diversidade, hoje, torna-se rica fonte de discussão acerca das mediações do sujeito queer - estranho, irregular, torto, deficitário, menor - para além do sistema hegemônico. Aqui, seria a diversidade das alternativas de diferenças, que subtraem estrategicamente a (inter)subjetividade dos enunciados. Nesse caso, a dinâmica aumenta a capacidade de alteridade e diferença, ao propor "novos/outros" caminhos. São variáveis necessárias a essa "nova/outra" condição adaptativa, mais coerente com a vida humana. Logo, como em Bauman (2015), Canclini (2016) e Eagleton (2016), o mercado-mídia coisifica, objetifica o valor humano em mercadoria/produto.

\footnotetext{
A intoxicação midiática é o que melhor consegue condicionar as massas nas grandes e nas pequenas coisas, distorcendo os valores, incutindo desejos, criando necessidades artificiais, induzindo medos e paixões, condicionando as escolhas políticas, econômicas, financeiras e estéticas (MASI, 2017, p. 328).
}

O viés econômico rege a comunicação e o entretenimento. E a inclusão é, dessa maneira, planejada para atrair consumidores e, por sua vez, trazem o lucro. Tal estratégia produz mais dualidades na questão da diversidade: ao mesmo tempo em que a dita "aceitação" social é ilusória, a inclusão ornamental acaba por acontecer no fim do processo. Ou seja, produzir uma mercadoria que atenda a demanda diversificada não significa que a empresa se preocupe com a diversidade em si. Mas, os consumidores acabam por ser "ornamentalmente incluídos" na sociedade do consumo através dela. Após tanto tempo órfãs de produtos que agraciem sua subjetividade e identidade, as minorias compram, usam, bebem e votam por aqueles que atenderam suas demandas.

A relação entre pessoas do mesmo sexo, por exemplo, indicia uma situação intima exibida pela mediação das redes sociais com a cultura digital e as tecnologias emergentes. Agora, público e privado enfrentam "novos/outros" arranjos, cujas instâncias distintas transmitem esse tipo de informação - como produção de conteúdo.

Em um viés paradoxal, uma imagem leve e tenaz expõe afetos e intimidades entre sujeitos no mercado-mídia. Elegem-se texturas contrastantes da diversidade multicultural como prioridade. Cada vez mais, a diversidade cultural/sexual contagia-se de alternativas temáticas. Propositalmente, a diversidade problematiza o sistema hegemônico a ponto de provocar uma 
reflexão sobre os referentes cotidianos da identidade sexual e de gênero, com feixes de efeitos de sentido. Quem sabe, por isso, o efeito da diversidade possa apavorar o sistema hegemônico.

Assim, a identidade sexual e de gênero, conforme Butler (2008) e Salih (2015), ultrapassa o senso comum e trabalha a subjetividade com alternativas/variáveis entre amizade, desejo, erótica, sedução, sensualidade, sexo etc. A diversidade requer o alargamento de "novas/outras" possibilidades que atravessam/confrontam convencionalidades. Essa noção de diversidade agrega diversos setores da sociedade. De modo ousado e impactante, a expectativa provoca uma ressignificação a respeito da condição humana no contemporâneo. O que dinamiza a visibilidade e a ação afirmativa a favor das comunidades de Lésbicas, Gays, Bissexuais, Transexuais, Queers e Intersexs (LGBTQI).

Minha intenção é explorar um tipo de voz e gênero literário que denomino "narrativa da diferença". Interesso-me em pensar o papel da cultura de mídia (literatura, cinema etc.) na inevitável construção do sujeito globalizado da pós-modernidade, cujo processo de subjetivação onipotente e universal se consolida por meio da negação da multiplicidade e da oposição a um Outro não sujeito imaginado que é impregnado com marcas da subcultura. (SANTOS, 2014, p. 104).

Longe de qualquer modelo normativo do sistema hegemônico, as relações de gênero, para a maioria das pessoas, ocorrem na dinâmica fragmentada de espaços e tempos. Logo, o reconhecimento das dimensões das desigualdades de gêneros, conforme Butler (2008), Salih (2015) e Preciado (2014), precisam ser investigados tendo em vista os "novos/outros" temas que se apresentam, para além do lugar comum. Nesse caso, a diversidade compreende fatores da desigualdade, sem necessariamente buscar uma equidade sociocultural e/ou política. A agudeza dessa exemplificação introduz a diversidade cultural/sexual, hoje, em consonância com a desigualdade social, em especial no Brasil. 
De acordo com Giannetti (2016, p. 98-99):

\begin{abstract}
A desigualdade não é um mal em si - o que importa é a natureza do caminho até ela. [...] a desigualdade reflete essencialmente os talentos, esforços e valores diferenciados dos indivíduos ou, ao contrário, ela resulta de um jogo viciado na origem e no processo, ou seja, de uma profunda falta de equidade nas condições iniciais da vida, da privação dos direitos elementares e/ou da discriminação racial, sexual, de gênero ou religiosa?
\end{abstract}

Das contradições enunciadas nessa ausência de equidade entre sujeitos, tal desigualdade afere o desiquilíbrio entre países desenvolvido e/ou subdesenvolvidos e se torna recorrente no cotidiano do mundo globalizado. A sociedade cada vez mais (de)marca-se pela globalização do chamado mercado-mídia. Conforme Piketty (2015), a desigualdade social retrata a disparidade econômica do capital - do padrão de vida -, diante das consequências que assolam a distribuição de renda no mundo globalizado, inclusive no país.

Para além da norma, a diversidade emana "nova/outra" lógica, não convencional, instituída pelo sistema hegemônico - o mainstream. Propositalmente, a diversidade problematiza o hegemônico a ponto de propor uma "nova/outra" reflexão sobre traços identitários com feixes de efeitos de sentido. Com isso, tal diversidade tenta fazer parte do cenário midiático, social e político, conforme Pelbart (2013; 2015), para se estabelecer enquanto sujeito que tem orgulho de si. Isso, inclusive, equivale interesse das comunidades LGBTQI.

Não há mais a ideia de destino, sina ou carma como simples desfecho do cotidiano. As chamadas minorias - uma falácia sócio-gramatical que necessita urgentemente de "nova/outra" definição, conforme Louro (2004), Muñoz (1999) e Santos (2014), reivindicam espaço e tempo que possam renegociar ou abolir normatividades hegemônicas. Como reiteração, são impostos padrões às minorias. O que pressupõe, ironicamente, os diferentes mais adequados socialmente no cotidiano.

Nesse caso, a política da diversidade permite que o/a outro/a possa ser diferente, ao convocar um pensamento sobre as (im)possíveis e inimagináveis variantes, cujas alternativas se proliferam. Na estratificação de pressupostos, conforme Pelbart (2015), a diversidade cultural/sexual fragmenta-se de substratos enunciados entre o Ser/Estar do sujeito contemporâneo, sobretudo no Brasil. Dessa maneira, a diversidade na sociedade contemporânea 
constitui, estrategicamente, determinada parcela de práticas socioculturais e/ou políticas com a inscrição de pressupostos, quando se almeja maior abrangência para equacionar as relações de amizade, desejo, erótica, sedução, sensualidade, sexo etc.

\begin{abstract}
Hoje os cientistas sociais utilizam a metáfora da rede para explicar todo tipo de relações, mediadas ou não pela tecnologia digital: as migrações, o trabalho, o sexo, a cultura a família... Creio que são analogias bem pobres, que limitam nossa capacidade de entender processos históricos de longa duração. Mas o mais interessante é pensar como essa transformação da compreensão das relações é afetada por nossa aspiração a viver em um mundo mais justo e menos alienado e pelo que acreditamos que devemos fazer para consegui-lo. (RENDUELES, 2016, p. 4).
\end{abstract}

Esse ideal de ser mais justo e menos alienado e pelo que acreditamos (re)dimensiona, então, a diversidade dividida entre alteridade e diferença. Até mesmo as políticas de "inclusão" parecem desaguar em um esforço simbólico/emblemático. Metaforicamente, uma parcela dita normativa da sociedade abre as portas para a entrada de diversidade, o faz timidamente.

\title{
Do corpo em questão
}

Segundo Louro (2004, p. 75), a noção poder determina lugares sociais e posições do sujeito mediante o corpo: "indicado, classificado, ordenado, hierarquizado e definido pela sua aparência, a partir dos padrões e referências, das normas, valores e ideias da cultura”. Dessa forma, corpos sociais ganham valor quanto mercadoria/produto e a sociedade privilegia corpos que se aproximam do padrão esperados pela hegemonia social. Ou seja, destacam os corpos que "valem mais", de acordo com o valor atribuído.

O corpo estabelecido como padrão da sociedade ocidental - homem-branco-cisheterossexual - torna-se o modelo regulador de padronagem a ser seguida e convoca, diretamente, o valor de cada pessoa por comparação com esse ideal. O sujeito, portanto, é determinado na sociedade, conforme Butler (2008), por um processo regulado de repetição de normas que tanto se oculta como impõe suas regras, por meio de produção de efeitos. Para Hoff (2016), quão mais distanciado do padrão, menos valor tem, portanto, menos acesso ao consumo social.

O corpo-coisa é marginalizado, interditado, confundido. Contra ele, justificam-se atos de violência, uma vez que tem menos valor como corpo humano. Pensar desse jeito, ao levar 
em consideração a sociedade heteronormativa, indica que o heterossexual teria maior liberdade de escolha. Isso permitiria um agenciamento menos conflituoso com o padrão, uma vez que sua imagem estaria mais próxima do modelo ideal. Para a sociedade, esse sujeito hétero existe, tem um caráter definido, ou seja, é previsível e finito. Mas, cuidado leitor/a, pois isso é apenas um referente.

Já o sujeito da diferença - sexual, étnica/racial, cultural e social - busca possibilidades de negociar/agenciar sua vivência com a alteridade, a qual responde de modo dinâmico. E o mundo inteiro torna-se um lugar estranho, segundo Canclini (2016), pois já ocupa qualquer espaço/tempo como sujeito heterossexual, para se comunicar. Afinal, falar e se expressar, de maneira diferente, parece ser inválido pelo sistema. E os costumes corriqueiros são subordinados às leis impostas pelo sistema hegemônico. O sujeito da diferença, para Hoff (2016), quase inexiste nesse sistema, que utiliza de discursos e ações de limitação, silenciamento e invisibilização. $\mathrm{O}$ acesso à informação, à cultura representativa de sua realidade, aos meios de arte e expressão são limitados ao máximo, numa tentativa de silenciar o sujeito.

De acordo com Preciado (2014), a contrassexualidade emerge-se como uma teoria do corpo - os postcuerpos (pós-corpos). São corpos falantes que ditam a cultura, pois experimentam tecnologicamente a vida humana, em sua natureza discursiva. Conforme Foucault (2011), a/o autor/a inscrevem uma noção de corpo que abarca arquivos orgânicos da história da humanidade.

Sobre a tecnologia do sexo, Preciado (2014, p. 147) escreve:

O termo tecnologia (cuja origem remete à techné, ofício e arte de fabricar, opondo-se a physis, natureza) coloca em funcionamento uma série de oposições binárias: natural/artificial, órgão/máquina, primitivo/moderno, nas quais o "instrumento" joga um papel de mediação entre termos de oposição.

Ou seja, para Preciado (2014, p. 16):

O sistema sexo/gênero é um sistema de escritura. O corpo é um texto socialmente construído, um arquivo orgânico da história da humanidade como história da produção-reprodução sexual, na qual certos códigos se naturalizam, outros ficam elípticos e outros são sistematicamente eliminados ou riscados. 
Isso pressupõe um debate contundente à revisão sobre o sujeito no campo contemporâneo da comunicação e da cultura. Santos (2014), ao discutir a produção da sociedade heteronormativa, cita um poema de Frye, em que a filósofa descreve o real como a visão do Rei. Ou seja, a visão do poder centralizador invisibiliza o sujeito à margem da sociedade heteronormativa. Logo, se a realidade é delimitada pelo que o sistema hegemônico reconhece, o sujeito da diferença não existe. Hoje, questiona-se sobre a realidade, além de ultrapassar as rupturas convencionais da ideologia política e da transformação social.

Emerge, então, o que Oliveira (2016) chama de "protagonismo de resistência", ou seja, o sujeito - questionador desse padrão excludente - reivindica sua (des)identidade, como esclarece Muñoz (1999). Instaura-se um posicionamento flexível, flutuante. Por isso, resistir (de)marca alteridade e diferença, as quais ressaltam variantes legítimas na condição humana do sujeito em sua sujeição (inter)subjetiva. Ou melhor, ainda, na experiência vivenciada pela informação.

Para Bauman (2015), a resistência externa (do corpo) aos nossos próprios desejos denomina-se realidade. $\mathrm{O}$ corpo, então, surge como embatimento efervescente, resistente ao sistema hegemônico. Ou seja, a partir do momento que há uma tentativa de invisibilizar a diversidade pela hegemonia, o silêncio gradual do corpo - periférico, marginalizados, discriminado - passa a estar presente. Disso, o corpo ganha força de combate.

Contraditoriamente à subalternidade, há uma resistência. Resistir não pode nem deve ser uma mera resposta ao sistema hegemônico, pois isso significaria "dar ouvidos" e respaldar a opressão. É muito mais que isso, sem dúvida. Resistir seria lutar e combater as dificuldades, de forma articulada e inteligente, a partir da elaboração de estratégias, capazes de se (re)apropriar do discurso. Uma voz que fala. A ideologia, por exemplo, permeia a condição de uma voz que - para além da denúncia - equaciona a maneira mais viável para se constituir discursividades que expressem uma política da diversidade.

Garcia (2014, p. 19) afirma que "a diferença extrapola as meras convenções sociais para dar lugar à natureza humana. A diferença continua sendo um estigma - mesmo que vendável”. E a normatividade continua sendo a regra hegemônica. Nega-se a presença, porém, o sujeito da diferença ocupa os espaços urbanos, tem acesso às tecnologias emergentes, convive nos espaços 
virtuais, opina, vota, reivindica, entre outros. Sua ausência, para Gumbretch (2015) também o faz presente.

Masi (2017, p. 100), ao escrever sobre a desorientação sexual, na atualidade, comenta: “o corpo, como dado imutável designado a cada ser vivo pela natureza, hoje, graças à engenharia genética, à cirurgia plástica e à dietologia. Tornou-se uma simples hipótese sobre a qual se pode intervir com modificações sempre mais substanciais." e conclui: "as homossexualidades masculina e feminina, perseguidas por séculos como práticas desviantes ou como patologias infamantes, já apareceram como condições normais ou opção lícita, com direitos iguais da heterossexualidade" (MASI, 2017, p. 100). Tal equiparação pode ser apenas um discurso político a ser implementado cada vez mais na mídia - como repetição que se funde verdade. Logo, é preciso trabalhar, de fato, para que a diversidade prevaleça na sociedade.

Essa forma contemporânea de o sujeito encarar a si mesmo e a civilização global perfaz uma experimentação plural, fora dos limites impostos pelo sistema hegemônico e torna sua vivência uma alternativa ao sentido. Gumbrecht (2015) descreve a despreocupação com o sentido, e sim com o efeito como produção de presença. Ou seja, os tipos de eventos e processos nos quais se inicia ou se intensifica o impacto dos objetos "presentes". Para este autor, trata-se de observar e considerar o fenômeno do corpo diante da relação que se mantem com o ambiente. A possibilidade de ser afetado, materialmente, com a disposição personificada pelo/com o corpo. Essa presença, portanto, potencializa o protagonismo da resistência pela ausência no sistema hegemônico.

\section{Da dinâmica queer}

A dinâmica queer aparece como adjetivação/caracterização para o sujeito da diferença sexual e de gênero, sem atenuar qualquer alternativa plausível. Disso, a diversidade existe em uma sociedade marcada por padrões de comportamento/aparência. Talvez, esses padrões pontuam algumas fronteiras entre o normal e o queer (estranho). Dessa forma, (re)considera-se uma produção variada e sem-fim de denominações, rótulos, preconceitos, marginalização e elitismo. Quem sabe, seria uma fronteira tênue que o (in)aceitável socialmente. 
Segundo Santos (2014), queer, em tradução livre para o português, significa "estranho" e era anteriormente utilizada como insulto nos Estados Unidos, durante a crise da epidemia HIV/AIDS. Historicamente, queer seriam as pessoas não heterossexuais que, por esse motivo, estariam na "zona de risco" de contração do vírus. Pessoas eram oprimidas e marginalizadas pelo governo, que recusava o atendimento a elas pelas unidades de saúde. Isso gerou forte reação entre ativistas (LGBTQI) na época, ao fazer surgir movimentos sociais combativos, que utilizavam a palavra queer ao contrário, como afirmação de uma identidade alternativa ao padrão heteronormativo.

Santos (2014) adverte que a vantagem da comunidade LGBTQI é justamente sua diferença. E o autor afirma que essa diferença deveria ser usada como oportunidade de criar os próprios modelos, desvinculados da normatividade heterofalocêntrica. Portanto, não seria uma resposta ou uma subversão, mas um modo "novo/outro" (diferente/divergente) de existir e discutir a vida. O lugar da diferença, nesse panorama, segundo Garcia (2014, p. 17), "pontuase pela ambiguidade que reúne em si um modo intrínseco de identidade e alteridade. Contudo, a diferença não seria uma absoluta alteridade, mas antes se vê marcada pelo movimento metonímico da repetição, numa estranha e oscilante armadilha identificatória".

A diferença, nesse contexto, aponta para variáveis que compreendem "novos/outros" universos discursivos. A queerness - essa força inerente do queer - emerge como derivativa do Ser/Estar do sujeito da diferença (queer); e envolve traços (des)identitários: o corpo, a roupa, a voz, a performance e as relações de (in)visibilização. O sujeito queer torna-se protagonista da resistência contra a heteronormatividade imposta pelo sistema. E a queerness, por sua vez, seria o contraproduto da reorganização social, que quebra com o poder hegemônico com um tom de pastiche, paródia e/ou citação.

As normas e as tradições são paulatinamente (re)configuradas e parodiadas em "novas/outras" possibilidades do estado democrático, em traduções que expõem a fragilidade do sistema hegemônico. Exemplos de resistência e transgressão/subversão das normas pelo protagonista queer são a constituição familiar contemporânea, a atualização do feminismo e do transativismo, bem como as manifestações artivistas - no encontro, mais recente entre arte e ativismo dos movimentos sociais. Essa (re)dimensão queer desafia qualquer perspectiva conservadora para ampliar a sensibilidade da experiência humana. 
Com as tecnologias emergentes e práticas sociais de reprodução humana - fertilização in vitro, tratamentos hormonais para indução de ovulação, gestação de substituição ("barriga de aluguel"), as possibilidades da constituição familiar também foram ampliadas deliberadamente. Não há mais justificativas sobre a reprodução humana que sustentem o argumento como: para gerar filhos, é necessário, invariavelmente, um homem e uma mulher.

Preciado (2014) discute que as relações de filiação são ressignificadas ao se propor uma paternidade (e/ou maternidade), sem necessitar do sexo para estabelecer laços familiares. Para além do biológico, essa lógica acontece tanto de filhos para pais, no caso de pais que tenham mesmo gênero; quanto de pais para filhos, na aceitação e ou reconhecimento das crianças intersexuais, transgêneras e homossexuais. Tal situação complexa extrapola o hegemônico e desafia a condição adaptativa da vida contemporânea. Conforme comenta Salih (2015, p. 135):

Aquilo que Butler chama de "a crescente teatralização da indignação política em reação à negligência fatal dos legisladores relativamente à questão da Aids" é sintetrizado pela apropriação do termo "queer", um performativo interpelativo que, de um insulto, se transformou num signo linguístico de afirmação e de resistência.

E complementa:

Embora continue vendo potencial subversivo na contingência e na capacidade de ressignificação do signo, Butler também está consciente de que a citação não é necessariamente subversiva e chama a atenção para o fato de que certas “desnaturalizações da norma heterossexual contribuem, na verdade, para reforçar a hegemonia heterossexual.

A resistência como autoposicionamento, assim, afirma o ato performativo do queer, em busca de uma (re)solução contra o sistema hegemônico. Seria uma recusa de corresponder imediatamente ao chamado convencional. Além de apaziguar as inflamadas demandas inclusivas inerentes à diversidade, as estratégias discursivas produzem "novos/outros" desdobramentos enunciativos da diversidade: uma atualização da vida.

Especificamente em relação ao feminismo contemporâneo e transativismo, é recorrente o movimento de transgressão/subversão: uma "nova/outra" roupagem proposta pelo pósfeminismo, segundo Butler (2008), a partir da teoria da performatividade de gênero. Entre diferentes vertentes, conforme Rendueles (2016) e Yúdice (2016), as discussões de gênero ganham espaço de reverberação no virtual, o ciberativismo. Esses movimentos sociais 
(hipermidiáticos) utilizam páginas nas redes sociais na internet para transmitir mensagens curtas, muitas vezes atreladas às imagens impactantes ou engraçadas, ao expor/denunciar situações de machismo e de violência. Além da denúncia, muitas dessas páginas também reservam espaço para interação (comentários nos posts ou grupos de discussão), na intenção de fortalecer as mulheres e pessoas trans com informações de como proceder em situações machistas, bem como se posicionar em relacionamentos abusivos, como denunciar assédio, violência, transfobia etc.

Já nos espaços de arte, o corpo queer, por meio da performance, abre "novos/outros" caminho" além do sistema normativo. As normatizações que visam a padronização da população causam uma série de danos. Nesse âmbito, a diversidade parece ser autônoma, sem necessidade de regras - impossível de ser estagnada. A multiplicidade humana movimenta diferentes culturas e possibilita o desenvolvimento de seus enunciados (COORDENAÇÃO DE POLÍTICAS PARA A DIVERSIDADE SEXUAL, 2017).

Ao performar, o artista queer é consciente que seu corpo é consumido, objeto de entretenimento. A queerness é seu ato transgressor, a resistência nas entrelinhas. Como Santos (2014, p. 76) descreve, “apesar de não poder ser expressa/explicada na língua/estética do opressor, existe (e flutua) nas repetições e em tudo aquilo que não pode ser absorvido/contido pela linguagem/estética falocrática/heteronormativa". Ou seja, o artista queer, antes, renegado às fissuras do sistema, potencializa essa condição de corpo-coisa diferente e excede os limites do palco e a performance torna-se referência para um movimento de resistência e transgressão.

Por lidar com questões que tangem pontualmente a diversidade, o interesse dessa noção de sujeito queer acende vigor empírico com as estratégias discursivas, visto que geram chances de reflexão e escrita como produção de conhecimento atrelada à produção de subjetividade. Esse tipo de produção cresce como reflexo da produção de informação na atualidade. A potencialidade do queer, assim, delibera uma posição efetiva de deslocamentos e flexibilidades, inerentes às variantes de uma política da diversidade. 


\section{Considerações finais}

A identidade sexual e de gênero não ocorre diretamente na materialidade do corpo. Entretanto, não seria simplesmente um ato performativo como efeito de práticas culturaislinguístico-discursivas. Das (re)dimensões teóricas e políticas, paradoxalmente estratificam-se propriedades e/ou predicações transversais sobre corpo, gênero, identidade e performance que se encontram inseridos nas passagens abordadas neste estudo.

Essa escrita ensaística traz uma tessitura de ideias contrastantes a respeito de nossa diversidade multicultural, a qual deve ser privilegiada na agenda de debates das universidades brasileiras, na expectativa de ampliar o olhar da experiência humana. Inevitavelmente, ressaltase a abrangência desse olhar - em elaboração - e o esforço teórico-político de uma posição crítica sobre diversidade cujo desafio da linguagem emerge do cotidiano, sobretudo no Brasil.

Assim sendo, a diversidade dinamiza categoricamente visibilidade e ações afirmativas em prol das comunidades de Lésbicas, Gays, Bissexuais, Transexuais, Queers e Intersexs (LGBTQI). Inevitavelmente, há dilemas na sociedade contemporânea. Enquanto alguém senta para estudar (ler ou escrever ideias), pessoas LGBTQIs são ofendidas violentamente com agressões abusivas no país e no mundo, pois há uma enorme disparidade machista, homofóbica e racista para ser combatida. E não se trata, aqui, de registar apenas uma denúncia e/ou reivindicação dos Direitos Humanos de determinado grupo social vulnerável, mas de gerar um alerta crítico à ordem vigente da insegurança no nosso cotidiano.

Mais que orgânica, uma política da diversidade no campo contemporâneo da comunicação e da cultura experimenta a elaboração do pensamento profundo e tenta equacionar "novas/outras" chances de se refletir sobre a vida. Sendo assim, a compreensão do afeto e da afeição nas relações humanas permeiam esse tipo de debate.

Para finalizar, vale a pena ressaltar que este texto soma impressões e registros de uma articulação discursiva entre reflexão e escrita coletiva. Com pausas necessárias, pois pretendemos organizar e sinalizar, estrategicamente, instâncias sobre a diversidade. Desfechos intrigantes elencam recursos técnicos, estéticos e éticos desdobrados na diversidade atual, ao considerar aspectos econômicos, identitários, socioculturais e/ou políticos. 


\section{Referências}

BAUMAN, Zigmunt. A riqueza de poucos beneficia todos nós? Rio de Janeiro: Jorge Zahar, 2015.

BUTLER, Judith. Problemas de gênero: feminismo e subversão da identidade. Rio de Janeiro: Civilização Brasileira, 2008.

CANCLINI, Néstor Garcia. O mundo inteiro como lugar estranho. São Paulo: EdUSP, 2016.

COORDENAÇÃO DE POLÍTICAS PARA A DIVERSIDADE SEXUAL. Diversidade sexual e cidadania LGBT. 2. ed. São Paulo: IMESP, 2017. Disponível em:

<http://www.justica.sp.gov.br/StaticFiles/SJDC/ArquivosComuns/ProgramasProjetos/CPDS/ Cartilha_Diversidade.pdf>. Acesso em: 29 maio 2016.

EAGLETON, Terry. A morte de Deus na cultura. Rio de Janeiro: Record, 2016.

FOUCAULT, Michel. A coragem da verdade: o governo de si e dos outros II. São Paulo: Martins Fontes, 2011.

GIANNETTI, Eduardo. Trópicos utópicos. São Paulo: Cia. das Letras, 2016.

GUMBRECHT, Hans Ulrich. Nosso amplo presente: o tempo e a cultura contemporânea. São Paulo: Unesp editora, 2015.

GUMBRECHT, Hans Ulrich. Produção de presença. Rio de Janeiro: Contracampo, 2010.

GARCIA, Wilton. Arte homoerótica no Brasil: estudos contemporâneos. Revista estudos de gênero, Niterói: UFF, v. 12, n. 2, p. 131-163, 2012.

GARCIA, Wilton. Prefácio. In: SANTOS, Rick. PoÉtica da diferença: um olhar queer. São Paulo: Factash, 2014. p. 15-19.

HALL, Stuart. Identidade cultural pós-moderna. Rio de Janeiro: DP\&A, 2002.

HOFF, Tânia (org.). Corpos discursivos: dos regimes de visibilidade às biosociabilidades do consumo. Recife: Editora da UFPE, 2016

LAZZARATO, Maurizio. Signos, máquinas, subjetividades. São Paulo: SESCSP, 2014.

LOURO, Guacira Lopes. Um corpo estranho: ensaios sobre sexualidade e teoria queer. Belo Horizonte: Autêntica, 2004.

MASI, Domenico de. Alfabeto da sociedade desorientada. São Paulo: Objetiva, 2017. 
MUÑOZ, José Steban. Disidentifications: queers of color and the performance of politics. Minneapolis, London: Universitry of Minesota Press, 1999.

OLIVEIRA, Dennis. Novos protagonismos midiáticos-culturais: a resistência a opressão da sociedade da informação. REGIT - Revista de Estudos de Gestão, Informação e Tecnologia, Itaquaquecetuba, v. 6, n. 2, p. 17-37, jul./dez. 2016. Disponível em: <http://fatecitaqua.edu.br/revista/index.php/regit/article/view/ART5/pdf_57>. Acesso em: 27 nov. 2016.

PELBART, Peter Pál. O avesso do niilismo: cartografias do esgotamento. São Paulo: n1edições, 2013.

PELBART, Peter Pál. What is contemporary? Afterall, v. 38, p. 4-13-13, 2015. Disponível em: <http://www.afterall.org/journal/issue.39/what-is-the-contemporary>. Acesso em: 22 dez. 2015.

PIKKETY, Thomas. A economia da desigualdade. Rio de Janeiro: Intrínseca, 2015.

PRECIADO, Beatriz. Manifesto contrassexual. São Paulo: n. 1 edições, 2014.

RENDUELES, César. Sociofobia: mudança política na era da utopia digital. São Paulo: SESC edições, 2016.

SALIH, Sarah. Judith Butler e a teoria queer. Belo Horizonte: Autêntica, 2015.

SANTOS, Rick J. PoÉtica da diferença: um olhar queer. São Paulo: Factash Editora, 2014.

VARGAS LLOSA, Mario. La civilización del espetáculo: uma radiografia de nosso tempo e da nossa cultura. Buenos Aires: Afaguara, 2013.

YÚDICE, George. Os desafios do novo cenário midiático para as políticas públicas.

Observatório, São Paulo, n. 20, p. 87-113, jan./jun. 2016. Disponível em:

<http://d3nv1jy4u7zmsc.cloudfront.net/wp-content/uploads/2016/05/OBS20_BOOK_AFISSUU.pdf>. Acesso em: 21 nov. 2016.

Débora Mestre - Universidade de Sorocaba - UNISO. Sorocaba

| São Paulo | Brasil. Contato: dmrmestre@gmail.com

Paula Parra - Universidade de Sorocaba - UNISO. Sorocaba |

São Paulo | Brasil. Contato: parra.paula@gmail.com

Wilton Garcia - Universidade de Sorocaba - UNISO. Sorocaba

| São Paulo | Brasil. Contato: wilton.garcia@prof.uniso.br 